Article

\title{
Anti-Inflammatory and Anti-Oxidant Effects of Epilobium amurense subsp. cephalostigma via Activation of Nrf2/HO-1 and Inhibition of NF-KB/p38 MAPK Signaling in LPS-Stimulated Macrophages
}

\author{
Se-Yun Cheon ${ }^{1,2,+}{ }^{+}$, Hyun-Ae Kang ${ }^{1,+}$, Bo-Ram Jin ${ }^{1}$, Hyo-Jung Kim ${ }^{1}$, Yea-Jin Park ${ }^{1}$, Ren-Bo An ${ }^{3}$, Soo-Yong Kim ${ }^{4}$ \\ and Hyo-Jin An 1,*iD \\ 1 Department of Pharmacology, College of Korean Medicine, Sangji University, Wonju-si 26339, Korea; \\ chunsay1008@naver.com (S.-Y.C.); Kha5414@hanmail.net (H.-A.K.); wlsqh92@gmail.com (B.-R.J.); \\ hyojung_95@naver.com (H.-J.K.); wer0928@hanmail.net (Y.-J.P.) \\ 2 AmcoBio Inc., Nambusunhwan-ro, Gwanak-gu, Seoul 08758, Korea \\ 3 College of Pharmacy, Yanbian University, Yanji 133002, China; anrb@ybu.edu.cn \\ 4 International Biological Material Research Center, Korea Research Institute of Bioscience and Biotechnology, \\ 125 Gwahak-ro, Yuseong-gu, Daejeon 34141, Korea; soodole@kribb.re.kr \\ * Correspondence: sangjipharm@gmail.com; Tel.: +82-33-738-7503; Fax: +82-33-730-0679 \\ + Se-Yun Cheon and Hyun-Ae Kang are equal contributors.
}

Citation: Cheon, S.-Y.; Kang, H.-A.; Jin, B.-R.; Kim, H.-J.; Park, Y.-J.; An, R.-B.; Kim, S.-Y.; An, H.-J. Anti-Inflammatory and Anti-Oxidant Effects of Epilobium amurense subsp. cephalostigma via Activation of Nrf2/HO-1 and Inhibition of NF- $\kappa$ B/p38 MAPK Signaling in LPS-Stimulated Macrophages. Appl. Sci. 2021, 11, 11715. https://doi.org/ 10.3390/app112411715

Academic Editor: Giovanna Traina

Received: 9 November 2021

Accepted: 6 December 2021

Published: 9 December 2021

Publisher's Note: MDPI stays neutral with regard to jurisdictional claims in published maps and institutional affiliations.

Copyright: (c) 2021 by the authors. Licensee MDPI, Basel, Switzerland. This article is an open access article distributed under the terms and conditions of the Creative Commons Attribution (CC BY) license (https:// creativecommons.org/licenses/by/ $4.0 /)$.

\begin{abstract}
The genus Epilobium consists of approximately 200 species that are distributed worldwide. Some of these herbs have been used for the treatment of diarrhea, infection, irritation, and other disorders associated with inflammation. Unlike that of other Epilobium species, there is little scientific understanding of the pharmacological effect of Epilobium amurense subsp. cephalostigma (Hausskn.) C. J. Chen, Hoch \& P. H. Raven. In this study, we demonstrated the anti-inflammatory and antioxidative properties of an E. amurense 95\% ethanol extract (EACEE) in lipopolysaccharide (LPS)-stimulated RAW 264.7 macrophages, and observed the underlying mechanism of this effect. We measured the productions of nitric oxide (NO) and reactive oxygen species, and examined the actions of EACEE on transcription factors in the macrophages. EACEE reduced NO production and inducible nitric oxide synthase protein levels via the inhibition of the nuclear factor (NF)- $\mathrm{B}$ pathway. Additionally, EACEE suppressed redundant reactive oxygen species production and regulated nuclear factor erythroid 2-related factor 2/heme oxygenase-1 (Nrf2/HO-1) signaling. Furthermore, EACEE significantly inhibited the phosphorylation of p38 mitogen-activated protein kinase (MAPK). Overall, these results indicate that EACEE exerts anti-inflammatory and antioxidant effects via the activation of Nrf2/HO-1 and inhibition of NF-kB/p38 MAPK signaling.
\end{abstract}

Keywords: Epilobium amurense subsp. cephalostigma (Hausskn.) C. J. Chen, Hoch \& P. H. Raven; nuclear factor- $\mathrm{kB}$; nuclear factor erythroid 2-related factor 2; inflammation; reactive oxygen species

\section{Introduction}

The Epilobium genus (Onagraceae) consists of approximately 200 species that are distributed worldwide (e.g., Europe, America, Africa, and northern Asia). Epilobium species were used in folk medicine in Europe and North America. Because of its demollient and emollient properties, Epilobium herbs have been used for the treatment of diarrhea, infection, irritation, and inflammation. Additionally, the extract of Epilobium parviflorum and Epilobium roseum possess radical scavenging activity, which indicates the antioxidant effects of Epilobium herbs [1]. This evidence suggests that Epilobium herbs are potential anti-inflammatory agents. Epilobium amurense subsp. cephalostigma (Hausskn.) C. J. Chen, Hoch \& P. H. Raven, which is a flowering plant that grows in China and the Republic of Korea, is a member of the Epilobium genus [2]. Unlike those of other Epilobium species, the 
biological effects of E. amurense have not been assessed. Therefore, in the present study, to investigate the pharmacological effects of E. amurense belonging to Epilobium herbs, it was harvested at the flowering/fruiting stage, when it contains a high content of phenolic compounds with anti-inflammatory and antioxidant properties, and the whole plant was extracted with $95 \%$ ethanol.

Inflammation, one of the most important host defense mechanisms, protects against foreign pathogens and infectious agents, including viruses, bacteria, damaged cells, toxic compounds, and parasites [3]. They trigger inflammatory signaling, such as nuclear factorkappaB (NF-kB) and mitogen-activated protein kinase (MAPK) pathways. The immune system relies on two major complementary systems, the innate and adaptive immune systems. However, abnormal or maladaptive interactions between these systems lead to unhealthy responses, including asthma, allergy, and other inflammatory diseases [4].

Reactive oxygen species (ROS) are generated as byproducts of normal mitochondrial oxidative metabolism and homeostasis [5]. However, the overproduction of ROS is related to the progression of many inflammatory diseases, such as diabetic foot syndrome, cardiovascular disorders, and chronic inflammatory diseases [6]. To regulate the production of oxidants in cells, oxidants are counterbalanced by an antioxidant system [7]. Nuclear factor erythroid 2-related factor 2 (Nrf2) is a transcription factor that regulates the expression of antioxidants that protect against oxidative stress and toxic electrophiles produced during injury and inflammation [8,9]. Before being activated by oxidants, Nrf2 is suppressed by Kelch-like erythroid cell-derived protein with CNC homology-associated protein 1dependent ubiquitination-proteasomal degradation [10]. Nrf2 affects the production of ROS via the regulation of several stress response proteins, including heme oxygenase- 1 (HO-1) and NAD(P)H:quinone oxidoreductase-1 (NQO-1) [5]. ROS are also produced in response to the activation of NADPH oxidase (Nox). The Nox family has several isoforms, among which Nox4 is the main isoform that generates and activates $\mathrm{H}_{2} \mathrm{O}_{2}$, an ROS [11,12]. However, the role of Nox4 in inflammation remains controversial because it has both inflammatory and anti-inflammatory activities. Thus, the appropriate regulation of ROSmediated Nox4 signaling may effectively modulate inflammatory responses; however, the underlying mechanisms during the proinflammatory phase are largely unknown.

Therefore, in this study, we investigated the pharmacological effects of an E. amurense 95\% ethanol extract (EACEE) on RAW 264.7 macrophages and the molecular mechanism(s) involved in its anti-inflammatory and antioxidant activities.

\section{Materials and Methods}

\subsection{Chemicals and Reagents}

Dimethyl sulfoxide, sodium nitrite, thiazolyl blue tetrazolium bromide, and all other chemicals were purchased from Sigma-Aldrich (St. Louis, MO, USA). Dulbecco's modified Eagle's medium (DMEM), fetal bovine serum (FBS), and penicillin-streptomycin were purchased from Life Technologies, Inc. (Grand Island, NY, USA). Antibodies for inducible nitric oxide synthase (iNOS), cyclooxygenase-2, phospho-extracellular signal-regulated kinases (p-ERK), ERK, phospho-c-Jun N-terminal kinase (p-JNK), JNK, phospho-p38 (p-p38), p38, p65, poly [ADP-ribose] polymerase- $1, \alpha$-tubulin, HO-1, Nox4, NQO1, and $\beta$-actin were purchased from Santa Cruz Biotechnology, Inc. (Dallas, TX, USA). Horseradish peroxidase-conjugated secondary antibodies were obtained from Jackson ImmunoResearch Laboratories, Inc. (West Grove, PA, USA).

\subsection{Preparation of EACEE}

E. amurense was obtained from the International Biological Material Research Center of the Korea Research Institute of Bioscience and Biotechnology (KRIBB, Daejeon, Korea). Whole plants of E. amurense were collected at the flowering/fruiting stage in An-tu, Jilin Province, China, in August 2012 and identified by Prof. Hui-zi Lv, a taxonomist at Yanbian University (Supplementary Figure S1). A voucher specimen (accession number KRIB0044858) of the plant was deposited in the herbarium of KRIBB. The E. amurense 
sample $(50 \mathrm{~g})$ was extracted twice with $95 \%(v / v)$ ethanol in water under reflux conditions for $3 \mathrm{~h}$. The combined $95 \%$ ethanol extracts were filtered with absorbent cotton and concentrated under reduced pressure. The recovery rate reached $10.1 \%$. For further use, the extract was lyophilized and stored at $-20^{\circ} \mathrm{C}$.

\subsection{Cell Culture}

RAW 264.7 murine macrophages were purchased from the Korea Cell Line Bank (Seoul, Korea). The macrophages were cultured in DMEM supplemented with $10 \%$ FBS, penicillin $(100 \mathrm{U} / \mathrm{mL})$, and streptomycin $(100 \mu \mathrm{g} / \mathrm{mL})$ in a humidified environment with $5 \% \mathrm{CO}_{2}$ at $37^{\circ} \mathrm{C}$.

\subsection{MTT Assay}

Cells were treated with EACEE $(15.62-125 \mu \mathrm{g} / \mathrm{mL})$ and incubated overnight. Then, MTT solution $(5 \mathrm{mg} / \mathrm{mL}$ ) was added for $4 \mathrm{~h}$. After aspirating the supernatant, the formazan product was dissolved in DMSO, and the extent of cytotoxicity was measured at $570 \mathrm{~nm}$ using a BioTek ${ }^{\mathrm{TM}}$ Epoch microplate spectrophotometer (Winooski, VT, USA).

\subsection{NO Assay}

$\mathrm{NO}$ content was analyzed indirectly by measuring the nitrite in the supernatants of cultured RAW 264.7 cells using the Griess reagent (1\% sulfanilamide in $5 \%$ phosphoric acid, $1 \% \alpha$-naphthylamide in $\mathrm{H}_{2} \mathrm{O}$ ). RAW 264.7 cells were seeded in a 24-well plate at a density of $5 \times 10^{5}$ cells per well and treated with 12.5, 25, or $50 \mu \mathrm{g} / \mathrm{mL}$ EACEE for $1 \mathrm{~h}$. After preincubation of the extract, the cells were stimulated with $1 \mu \mathrm{g} / \mathrm{mL}$ lipopolysaccharide (LPS) for $48 \mathrm{~h}$. A $50 \mu \mathrm{L}$ aliquot of cell culture media was mixed with $50 \mu \mathrm{L}$ of Griess reagent in a 96-well plate. This mixture was incubated at $24 \pm 3{ }^{\circ} \mathrm{C}$ for $15 \mathrm{~min}$ and nitrite content was measured at $540 \mathrm{~nm}$ using an Epoch microplate spectrometer (Biotek, VT, USA).

\subsection{Western Blot Analysis}

Cells were treated with PRO-PREP ${ }^{\mathrm{TM}}$ protein extraction solution (Intron Biotechnology Inc., Seong-nam, Korea) for $10 \mathrm{~min}$ on ice to induce cell lysis. The lysates were centrifuged at $11,000 \times \mathrm{g}$ for $20 \mathrm{~min}$ at $4{ }^{\circ} \mathrm{C}$ and the supernatant was transferred to a $1.5 \mathrm{~mL}$ fresh microtube. The protein concentration was measured using the Bio-Rad protein assay reagent according to the manufacturer's instructions (Bio-Rad, Hercules, CA, USA). The prepared sample (10-30 $\mu \mathrm{g}$ of protein) was separated on an $8-10 \%$ sodium dodecyl sulfate-polyacrylamide gel and transferred to a polyvinylidene difluoride membrane. The membrane was incubated for $1 \mathrm{~h}$ with $2.5 \%$ or $5 \%$ skim milk at $22 \pm 3{ }^{\circ} \mathrm{C}$, followed by overnight incubation with primary antibodies (1:1000 dilutions) at $4{ }^{\circ} \mathrm{C}$. The membranes were washed three times with Tween 20/Tris-buffered saline (T/TBS). Next, they were incubated with horseradish peroxidase-conjugated secondary antibodies (1:2500 dilutions) for $2 \mathrm{~h}$ at $22 \pm 3{ }^{\circ} \mathrm{C}$. After rinsing the blots three times with T/TBS, the immunodetection bands were developed with an enhanced chemiluminescent solution (Ab Signal, Seoul, Korea).

\subsection{Intracellular ROS Assay}

The generation of ROS was measured using an oxidative stress kit (Merck Millipore, Darmstadt, Germany) according to the manufacturer's protocols. Briefly, after culture and treatment, cells were incubated with the oxidative stress working solution and the proportion of ROS-positive cells was measured using the Muse ${ }^{\circledR}$ Cell Analyzer (Merck Millipore, Darmstadt, Germany).

\subsection{Statistical Analysis}

Data are expressed as the mean \pm standard deviation (S.D.) of three experiments. Statistical significance was determined by Dunnett's post hoc test for ANOVA using GraphPad Prism software (version 5.01). Differences between groups were considered significant at $p<0.05$. 


\section{Results}

\subsection{EACEE Inhibited NO Production and iNOS Protein Expression in LPS-Stimulated RAW} 264.7 Macrophages

To investigate the cell viability of EACEE in RAW 264.7 macrophages, we conducted the MTT assay. EACEE had significant toxicity over $62.5 \mu \mathrm{g} / \mathrm{mL}$ (Figure 1A). Therefore, we performed further studies using the nontoxic concentrations of EACEE $(12.5,25$, and $50 \mu \mathrm{g} / \mathrm{mL}$ ). iNOS, an enzyme that produces NO, is activated during the inflammatory response and oxidative stress [13]. To observe the inhibitory effect of EACEE on NO production in LPS-stimulated macrophages, cells were pretreated with EACEE for $1 \mathrm{~h}$ and stimulated with LPS for $48 \mathrm{~h}$. EACEE exerted dose-dependent inhibitory effects on NO release in LPS-stimulated cells (Figure 1B). In particular, EACEE $(50 \mu \mathrm{g} / \mathrm{mL})$ suppressed excess NO production by $40.5 \%$ in LPS-stimulated macrophages, which is superior to the effect of N6-(1-Iminoethyl) lysine (NIL, positive control). Stimulation with LPS significantly increased iNOS protein expression compared with that in vehicle-treated cells $(1.00 \pm 0.03$ vs. $0.02 \pm 0.048)$. Compared with those in LPS-stimulated macrophages, macrophages treated with 12.5, 25, and $50 \mu \mathrm{g} / \mathrm{mL}$ EACEE showed significantly reduced iNOS protein levels, by $17.72 \%, 18.27 \%$, and $23.70 \%$, respectively (Figure $1 \mathrm{C}$ ).

A

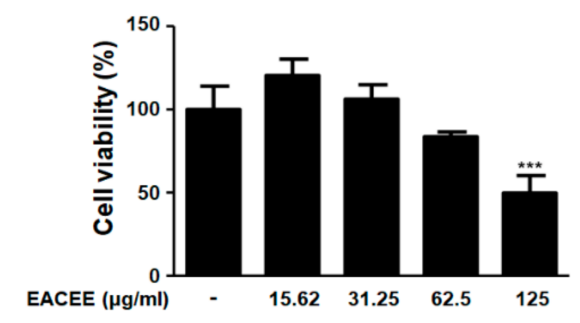

C

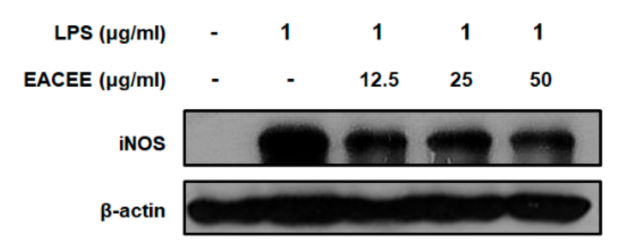

B
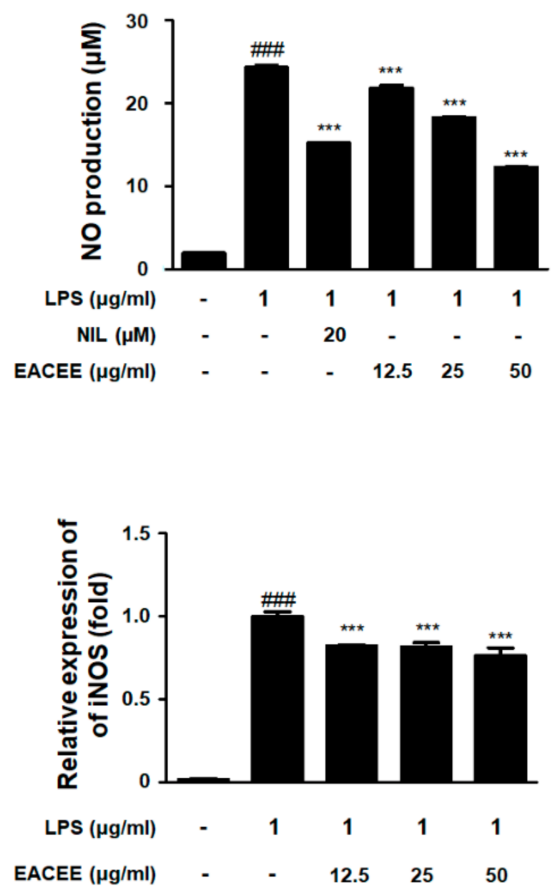

Figure 1. Effect of EACEE on cell viability and NO release in LPS-stimulated RAW 264.7 macrophages. (A) Cytotoxicity of EACEE was measured in RAW 264.7 macrophages. Macrophages were incubated with various concentrations of EACEE $(15.82-125 \mu \mathrm{g} / \mathrm{mL})$ for $24 \mathrm{~h}$. (B) Amounts of NO in the cell culture supernatants were determined using the Griess reagents. NIL $(20 \mu \mathrm{M})$ was used as a positive control. (C) Protein levels of iNOS were determined using Western blotting. Densitometric analysis was performed using ImageJ software. Data are shown as mean \pm S.D. of three independent experiments. ${ }^{\# \# \# ~} p<0.001$ vs. vehicle-treated macrophages; ${ }^{* * *} p<0.001$ vs. LPS-stimulated macrophages.

\subsection{EACEE Regulated NF- $\kappa B$ Pathway in LPS-Stimulated RAW 264.7 Macrophages}

Generally, iNOS expression is induced by the NF-kB transcriptional factor [14]. To examine the phosphorylation or degradation of IKB- $\alpha$, we analyzed protein levels using Western blotting with specific antibodies. LPS-stimulated macrophages showed upregulated levels of pIкB- $\alpha$ and downregulated levels of IкB- $\alpha$. However, treatment with EACEE 
significantly suppressed pIкB- $\alpha$ production and restored IкB- $\alpha$ levels (Figure $2 \mathrm{~A}$ ). To determine whether EACEE treatment also contributes to NF- $\mathrm{kB}$ translocation, we separated the nucleus and cytoplasm fractions from cells and analyzed p65 protein levels using Western blotting. NF- $\mathrm{KB}$ p65 protein levels in the LPS-stimulated cells increased in the nucleus fraction, whereas treatment with EACEE significantly inhibited the translocation of NF- $\mathrm{kB}$ p65 (Figure 2B).

A
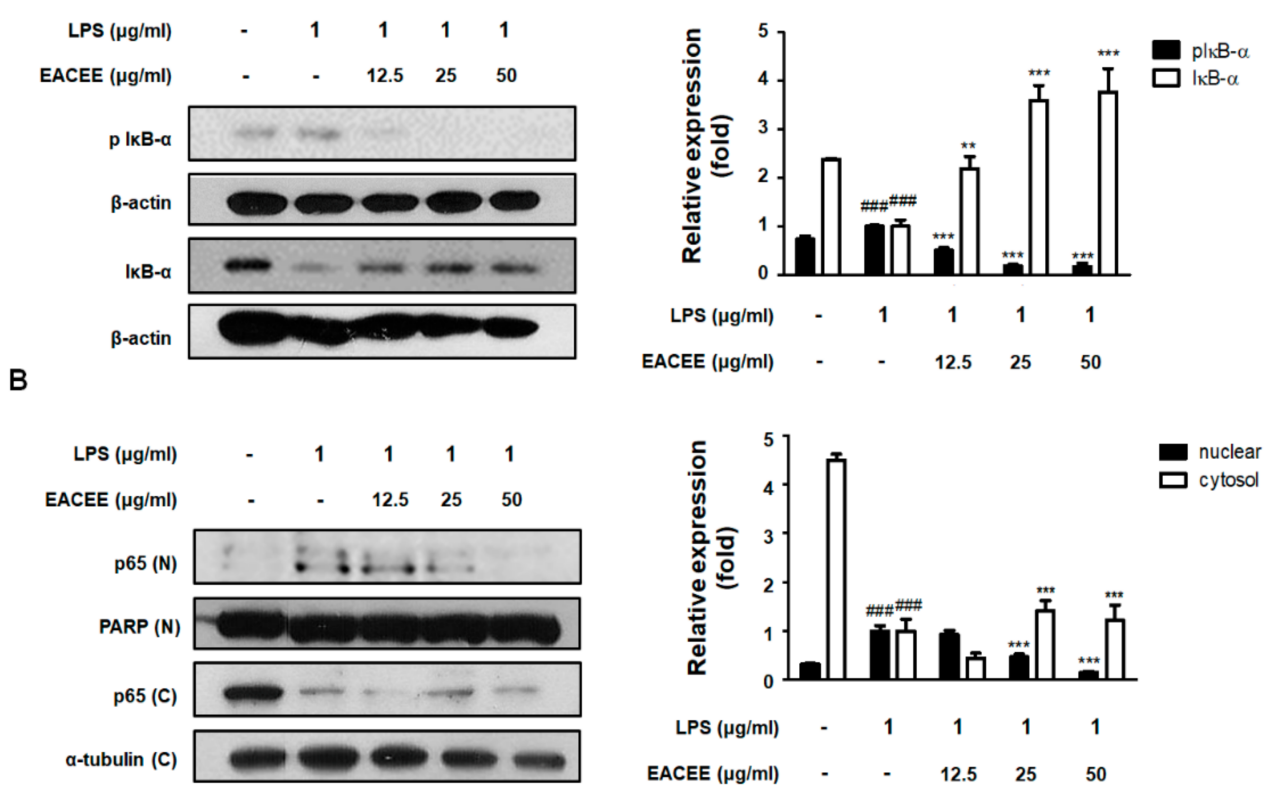

Figure 2. Effect of EACEE on NF- $\mathrm{B}$ activation in LPS-stimulated RAW 264.7 macrophages. Cells were pretreated with EACEE for $1 \mathrm{~h}$ and stimulated with LPS for $30 \mathrm{~min}$. Total protein was isolated

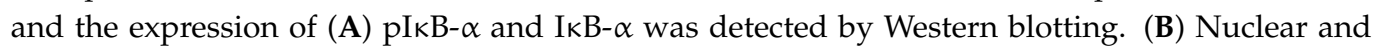
cytosolic proteins were isolated and the levels of p65 in each fraction were determined. Densitometric analysis was performed using ImageJ software. Data are shown as mean \pm S.D. of three independent experiments. ${ }^{\# \# \#} p<0.001$ vs. LPS-unstimulated macrophages; ${ }^{* *} p<0.01$ and ${ }^{* * *} p<0.001$ vs. LPS-stimulated macrophages.

\subsection{EACEE Inhibited Excess ROS Production in LPS-Stimulated RAW 264.7 Macrophages}

Previous studies have demonstrated a strong relationship between oxidative stress and inflammation [15]. To investigate the inhibitory effects of EACEE on LPS-induced redundant ROS production in macrophages, we conducted an oxidative stress assay using a cell analyzer. First, for the establishment of proper conditions, the cells were incubated with LPS for various times; then, the proportion of ROS-positive cells was measured using the Muse ${ }^{\circledR}$ oxidative stress kit. LPS-stimulated cells showed upregulated intracellular ROS levels compared with vehicle-treated normal cells after $3 \mathrm{~h}(p<0.001)$. However, pretreatment with EACEE significantly inhibited this excess ROS production in LPS-stimulated RAW 264.7 macrophages (Figure 3). 
A

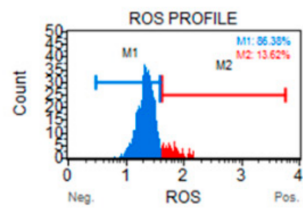

$\mathrm{Neg}$
LPS $(\mu \mathrm{g} / \mathrm{ml})$

ROS PROFILE

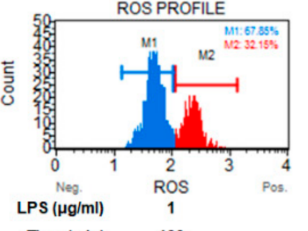

Time (min) $\quad 180$

B

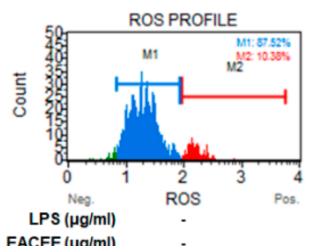

$\operatorname{EACEE}(\mu \mathrm{g} / \mathrm{ml})$

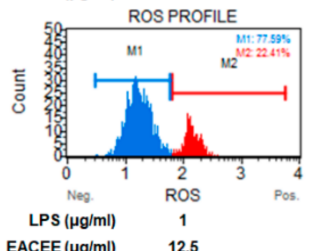

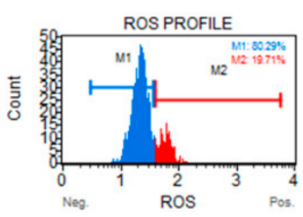

1
30

ROS PROFILE

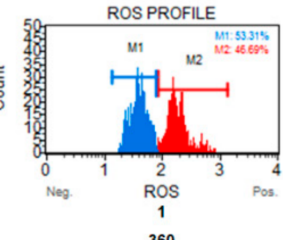

360
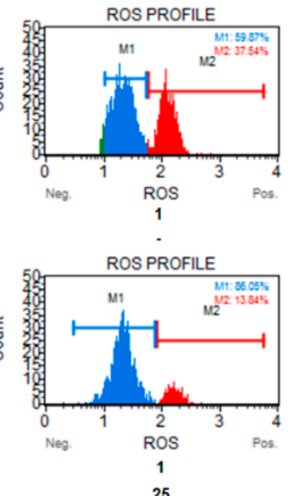

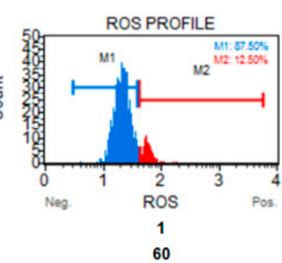

1
60

ROS PROFILE

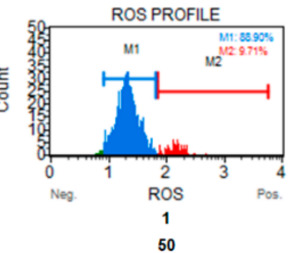

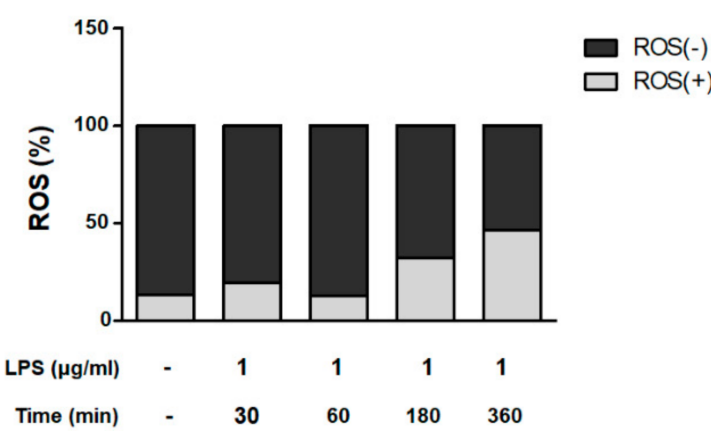

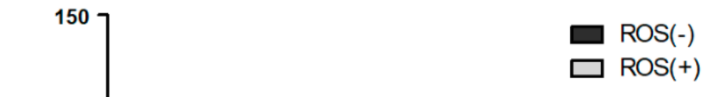

Figure 3. Effects of EACEE on ROS generation in LPS-stimulated RAW 264.7 macrophages. (A) Cells were incubated with LPS for various times and the levels of ROS were measured using the Muse ${ }^{\circledR}$ oxidative stress kit. (B) Cells were pretreated with or without indicated concentrations of EACEE for $1 \mathrm{~h}$ and incubated with LPS for 180 min. Data show relative percentages of ROS-negative and ROS-positive cells. Data are shown as mean \pm S.D. of three independent experiments.

3.4. EACEE Enhanced Nrf2 and HO-1 Protein Expression and Inhibited Overexpression of Nox4 in LPS-Stimulated RAW 264.7 Macrophages

The Nrf2/HO-1 signaling pathway has anti-inflammatory therapeutic potential [16]. To observe the effects of EACEE on oxidative stress-mediated Nrf2 signaling in LPSstimulated macrophages, we confirmed the protein expression of Nrf2, HO-1, and Nox4. The expression of Nrf2 protein was lower in LPS-stimulated cells than in vehicle-treated normal cells in the nucleus fraction, but this expression was significantly enhanced by EACEE (25 and $50 \mu \mathrm{g} / \mathrm{mL}$ ) treatment (Figure 4A). Additionally, EACEE $(50 \mu \mathrm{g} / \mathrm{mL})$ treatment significantly upregulated HO-1 protein expression compared with that in LPSstimulated cells (Figure 4B). Moreover, the protein expression of Nox4 was significantly higher after LPS stimulation than after vehicle treatment (1.00 \pm 0.21 vs. $0.48 \pm 0.06)$. In contrast, treatment with EACEE significantly inhibited the overexpression of Nox4 protein in a dose-dependent manner in LPS-stimulated cells (Figure 4C). 
A

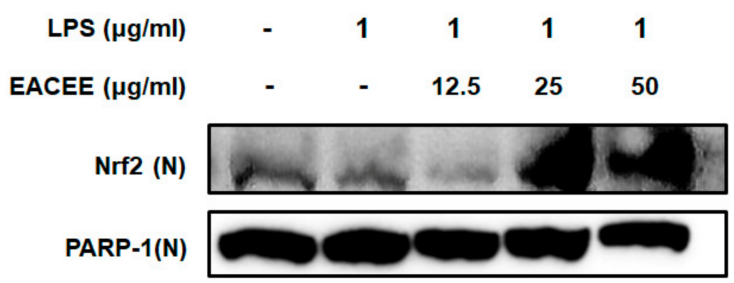

B

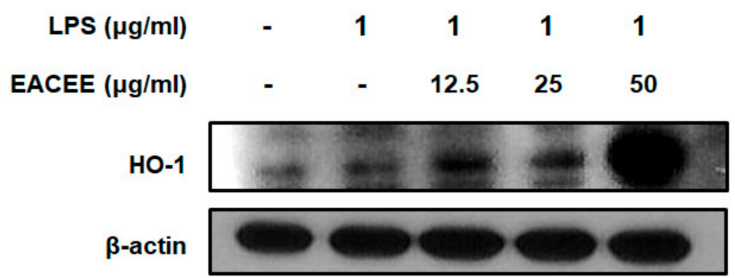

C

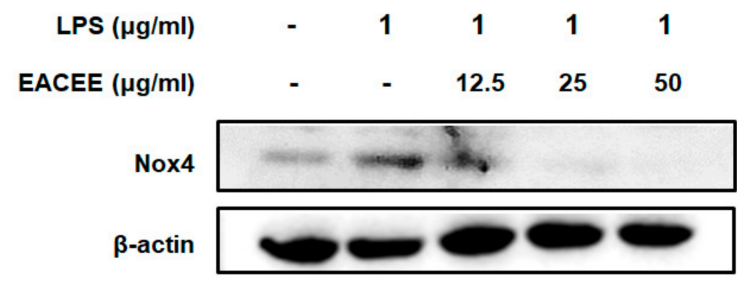

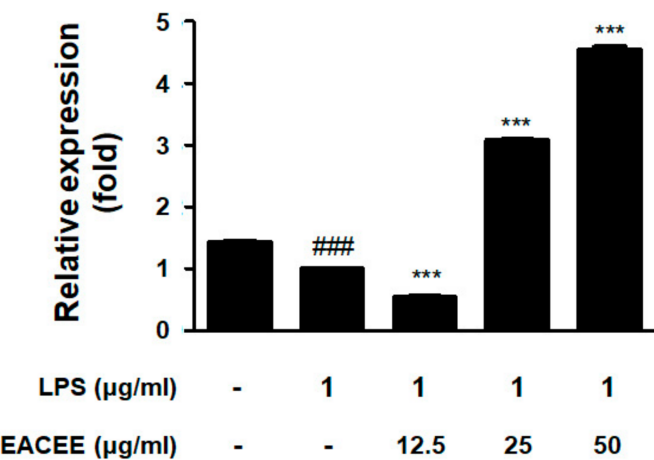
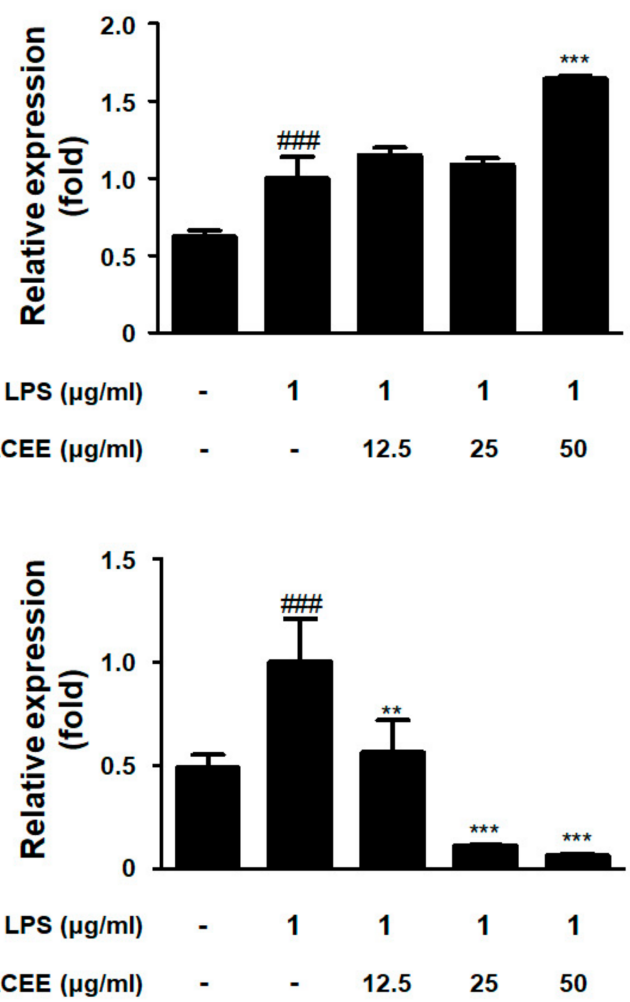

Figure 4. Effects of EACEE on Nrf2, HO-1, and Nox4 protein expression in LPS-stimulated RAW 264.7 macrophages. Cells were pretreated with EACEE for $1 \mathrm{~h}$ and stimulated with LPS for $12 \mathrm{~h}$. Total protein was isolated and the protein levels of (A) Nrf2, (B) HO-1, and (C) Nox4 were detected by Western blotting. Densitometric analysis was performed using ImageJ software. Data are shown as mean \pm S.D. of three independent experiments. ${ }^{\# \# \#} p<0.001$ vs. vehicle-treated LPS-stimulated macrophages; ${ }^{* *} p<0.01$ and ${ }^{* *} p<0.001$ vs. LPS-stimulated macrophages.

\subsection{EACEE Suppressed p-p38 MAPK Protein Expression in LPS-Stimulated RAW 264.7 Macrophages}

ROS induce the activation of MAPK pathways [17]. The phosphorylation of p38, ERK, and JNK was increased in LPS-stimulated macrophages compared with vehicle-treated cells $(p<0.001)$. In contrast, treatment with EACEE significantly decreased the level of p-p38 in LPS-stimulated macrophages (Figure 5A). However, EACEE did not affect the levels of p-ERK and p-JNK in LPS-stimulated macrophages (Figure 5B,C). 
A

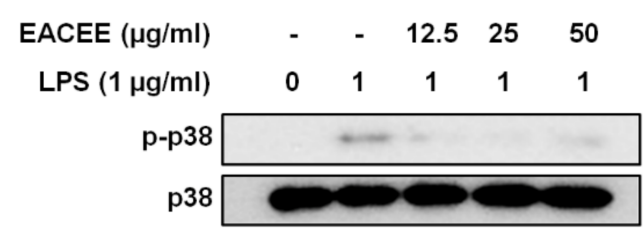

B

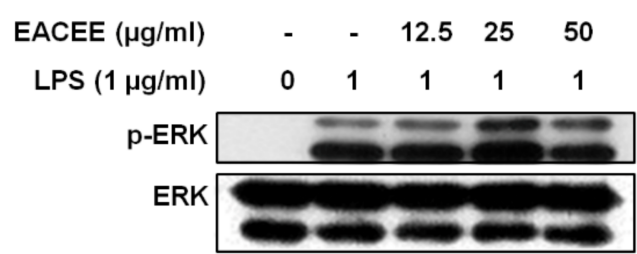

C

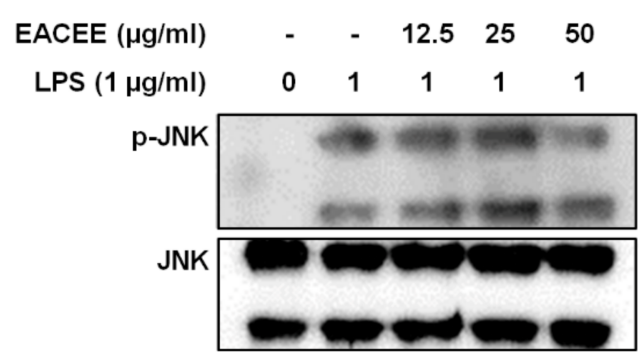

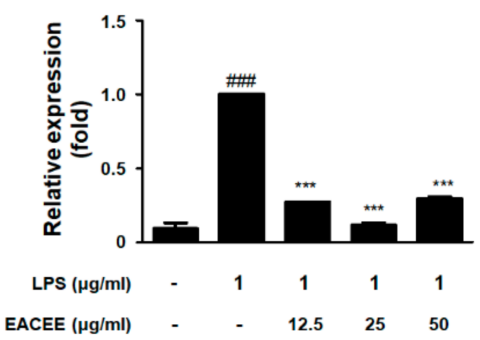
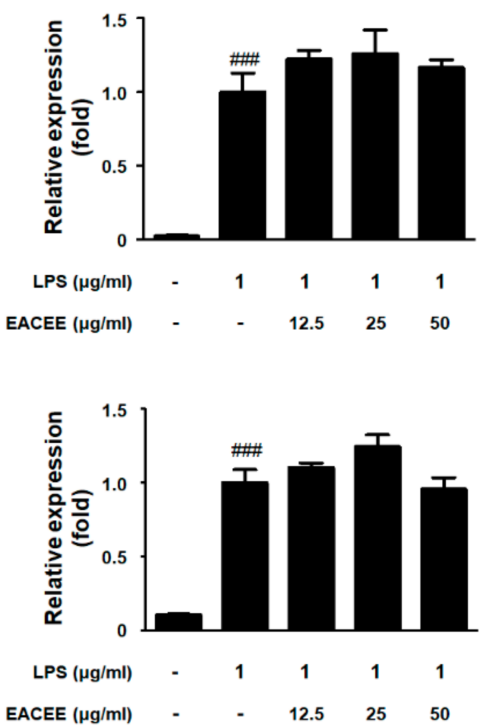

Figure 5. Effects of EACEE on MAPK pathway in LPS-stimulated RAW 264.7 macrophages. Cells were pretreated with EACEE for $1 \mathrm{~h}$ and stimulated with LPS for $1 \mathrm{~h}$. Levels of (A) p-p38 and p38, (B) p-ERK and ERK, and (C) p-JNK and JNK were detected by Western blotting. Densitometric analysis was performed using ImageJ software. Data are shown as mean \pm S.D. of three independent experiments. ${ }^{\# \#} p<0.001$ vs. vehicle-treated LPS-stimulated macrophages; ${ }^{* * *} p<0.001$ vs. LPSstimulated macrophages.

\section{Discussion}

Using a well-established cellular model of inflammation, the aim of our study was to evaluate the potential of EACEE to reduce the inflammatory effects of LPS, such as the activation of NF-kB and MAPK signaling pathways, in RAW 264.7 macrophages. Macrophages play a key role in innate and adaptive immune responses [18]. For this reason, macrophage cell lines are most commonly used to study inflammation and oxidative stress $[19,20]$. LPS is a potent stimulator of monocytes/macrophages, resulting in the activation of a series of inflammatory mediators [21].

Inductive stress produces ROS, NO, and signaling molecules that mediate cellular responses [22]. A previous study demonstrated the mechanism responsible for oxidative stress-induced iNOS gene transcription and promoter activity [23]. The overexpression of iNOS is likely to be an important factor in the development of inflammation-associated chronic diseases [24]. Our data indicated that LPS-induced NO production and iNOS expression are inhibited by EACEE treatment in macrophages (Figure 1). It can, therefore, be assumed that EACEE might inhibit the oxidative stress-induced development of inflammatory disease.

$\mathrm{NF}-\mathrm{kB}$ is a key transcription factor that mediates infection, inflammation, and cell proliferation. LPS exposure leads to the activation and translocation of NF- $k B$ into the nucleus of macrophages [25]. In our study, treatment with EACEE suppressed the activation of the NF- $\kappa B$ cascade and translocation of NF- $\kappa$ B p 65 in LPS-stimulated macrophages (Figure 2). An imbalance between the NF-kB and Nrf2 pathways contributes to several 
conditions, including septic shock, inflammatory diseases, and cancer. Numerous studies have noted that the Nrf2 and NF- $\kappa$ B pathways must cooperate through molecular reciprocal action [26,27]. Moreover, a previous study identified the crosstalk between NF- $\kappa \mathrm{B}$ p65 and Nrf2 in the redox system, in which p65 regulates the ubiquitination of Nrf2 [28]. Additionally, Nrf2 knockout macrophages exhibit an enhanced inflammatory response, whereas its upregulation inhibits proinflammatory responses via the regulation of the NF- $\kappa B$ pathway [29]. The results of our study also demonstrated a consistent association between NF-kB and Nrf2 pathways, showing the upregulation of Nrf2 protein expression by EACEE treatment in LPS-stimulated macrophages (Figure 4A). Interestingly, treatment with EACEE also upregulated HO-1 protein expression in LPS-stimulated macrophages (Figure 4B). HO-1, an Nrf2 target gene, is central to Nrf2-mediated NF-kB inhibition [26]. It can, therefore, be assumed that EACEE has anti-inflammatory and antioxidant activities via the simultaneous regulation of NF- $\mathrm{BB}$ and Nrf2 pathways.

A previous study has shown that LPS triggers oxidative burst in the Nrf2-dependent oxidative stress response [30]. Several studies have also documented that LPS stimulation drives the production of ROS and causes gene alterations in macrophages [31-33]. In our study, treatment with EACEE suppressed LPS-induced excess ROS production (Figure 3). Therefore, in agreement with the aforementioned studies, we predict that EACEE may exert ROS-scavenging activity via the regulation of the NF- $\mathrm{BB}$ and Nrf2 pathways in LPSstimulated macrophages. LPS-stimulated immune cells also lead to the activation of Nox4, which drives the development of innate immunity disorders [34]. Among Nox isoforms, Nox4 is an important enzyme for the generation of ROS under pathological conditions such as inflammation. Wang et al. demonstrated that Nox4 knockdown limits inflammatory responses in LPS-induced sepsis, which suggests a central role for Nox4 in inflammatory damage [35]. Our data also showed that Nox4 protein expression was overexpressed in LPS-stimulated macrophages, whereas these effects were abolished by treatment with EACEE (Figure 4C).

Generally, increased ROS production in a cell leads to the activation of ERKs, JNKs, and p38 MAPKs, but the mechanisms by which ROS can activate these kinases are unclear [17]. Considerable data suggest that the stimulation of monocytes/macrophages by LPS leads to the activation of MAPK, after which, ERK1/2 and p38 become tyrosinephosphorylated [36]. It has also been noted that the association of LPS with Toll-like receptor 4 increases gene expression through a Nox/ROS/p38 MAPK-dependent pathway [37]. In agreement with these studies, our results demonstrated a strong and consistent association between ROS/Nox and p38 MAPK signaling in LPS-stimulated macrophages. Our data also showed that LPS stimulation induced the phosphorylation of ERKs, JNKs, and p38 MAPKs in macrophages, whereas EACEE treatment exerted an inhibitory effect on the phosphorylation of p38 (Figure 5). These observations are supported by previous studies showing that p38 MAPK regulates the Nrf2-mediated antioxidant responsive element (ARE) pathway, in which the overexpression of p38 MAPK suppresses Nrf2induced ARE-dependent gene expression [38]. Overall, these results suggest that EACEE exerts anti-inflammatory and antioxidant effects via the regulation of the ROS-mediated NF-кB/Nrf2/Nox/p38 MAPK-dependent pathway.

\section{Conclusions}

The purpose of this study was to determine the pharmacological effects of EACEE in LPS-stimulated RAW 264.7 macrophages. The results of this study suggest that EACEE is a potent anti-inflammatory agent that executes its activities via the modulation of ROS/NF$\mathrm{kB} / \mathrm{Nrf} 2 / \mathrm{p} 38 \mathrm{MAPK}$ signaling. To the best of our knowledge, this is the first study that has documented the anti-inflammatory and antioxidant effects of E. amurense and the underlying molecular mechanisms of its effects.

Supplementary Materials: The following are available online at https:/ /www.mdpi.com/article/10 $.3390 /$ app112411715/s1, Figure S1: Specimen photographs of whole plants of E. amurense. 
Author Contributions: S.-Y.C., H.-A.K. and H.-J.A. conceived and designed the study. S.-Y.C., H.-A.K., B.-R.J., H.-J.K. and Y.-J.P. carried out the experiments and analyzed the research data. H.-J.A., S.-Y.C., H.-A.K. and H.-J.A. wrote the manuscript. R.-B.A., S.-Y.K. and H.-J.A. provided resources. All authors have read and agreed to the published version of the manuscript.

Funding: This research was supported by the Basic Science Research Program through the National Research Foundation of Korea (NRF), funded by the Ministry of Science, ICT and Future Planning (NRF2019R1A2C4070234); and the Research fund from Sangji University Graduate School.

Institutional Review Board Statement: Not applicable.

Informed Consent Statement: Not applicable.

Data Availability Statement: The datasets used and/or analyzed during the current study are available from the corresponding author on reasonable request.

Conflicts of Interest: The authors declare that they have no competing interests.

\begin{abstract}
Abbreviations
DMEM: Dulbecco's modified Eagle's medium; EACEE, Epilobium amurense 95\% ethanol extract; ERK, extracellular signal-regulated kinase; FBS, fetal bovine serum; HO-1, heme oxygenase-1; iNOS, inducible nitric oxide synthase; JNK, c-Jun N-terminal kinase; LPS, lipopolysaccharide; MAPK, mitogen-activated protein kinase; NF, nuclear factor; Nox, NADPH oxidase; NQO-1, NAD(P)H:quinone oxidoreductase-1; Nrf2, nuclear factor erythroid 2-related factor 2; ROS, reactive oxygen species; T/TBS, Tween 20/Tris-buffered saline.
\end{abstract}

\title{
References
}

1. Granica, S.; Piwowarski, J.; Czerwińska, M.; Kiss, A.K. Phytochemistry, pharmacology and traditional uses of different Epilobium species (Onagraceae): A review. J. Ethnopharmacol. 2014, 156, 316-346. [CrossRef]

2. Kungnip Sumogwŏn (Korea). Hanbando Chasaeng Singmul Yŏngŏirum Mongnokchip [English Names for Korean Native Plants]; Kungnip Sumogwŏn: Pocheon-si, Korea, 2015; 760p. Available online: https:/ / www.nlb.gov.sg/biblio/203966604 (accessed on 1 December 2021).

3. Libby, P. Inflammatory mechanisms: The molecular basis of inflammation and disease. Nutr. Rev. 2007, 65, S140-S146. [CrossRef]

4. Chen, L.; Deng, H.; Cui, H.; Fang, J.; Zuo, Z.; Deng, J.; Li, Y.; Wang, X.; Zhao, L. Inflammatory responses and inflammationassociated diseases in organs. Oncotarget 2018, 9, 7204-7218. [CrossRef]

5. Ray, P.D.; Huang, B.-W.; Tsuji, Y. Reactive oxygen species (ROS) homeostasis and redox regulation in cellular signaling. Cell. Signal. 2012, 24, 981-990. [CrossRef]

6. Yao, Y.; Zhang, H.; Wang, Z.; Ding, J.; Wang, S.; Huang, B.; Ke, S.; Gao, C. Reactive oxygen species (ROS)-responsive biomaterials mediate tissue microenvironments and tissue regeneration. J. Mater. Chem. B 2019, 7, 5019-5037. [CrossRef] [PubMed]

7. Ma, Q. Role of Nrf2 in Oxidative Stress and Toxicity. Annu. Rev. Pharmacol. Toxicol. 2013, 53, 401-426. [CrossRef] [PubMed]

8. Gold, R.; Kappos, L.; Arnold, D.L.; Bar-Or, A.; Giovannoni, G.; Selmaj, K.; Tornatore, C.; Sweetser, M.T.; Yang, M.S.M.; Sheikh, S.I.; et al. Placebo-Controlled Phase 3 Study of Oral BG-12 for Relapsing Multiple Sclerosis. N. Engl. J. Med. 2012, 367, 1098-1107. [CrossRef] [PubMed]

9. Baird, L.; Dinkova-Kostova, A.T. The cytoprotective role of the Keap1-Nrf2 pathway. Arch. Toxicol. 2011, 85, 241-272. [CrossRef]

10. Taguchi, K.; Motohashi, H.; Yamamoto, M. Molecular mechanisms of the Keap1-Nrf2 pathway in stress response and cancer evolution. Genes Cells 2011, 16, 123-140. [CrossRef]

11. Ushio-Fukai, M.; Nakamura, Y. Reactive oxygen species and angiogenesis: NADPH oxidase as target for cancer therapy. Cancer Lett. 2008, 266, 37-52. [CrossRef] [PubMed]

12. Bedard, K.; Krause, K.H. The NOX Family of ROS-Generating NADPH Oxidases: Physiology and Pathophysiology. Physiol. Rev. 2007, 87, 245-313. [CrossRef] [PubMed]

13. Sun, J.; Druhan, L.J.; Zweier, J.L. Reactive oxygen and nitrogen species regulate inducible nitric oxide synthase function shifting the balance of nitric oxide and superoxide production. Arch. Biochem. Biophys. 2010, 494, 130-137. [CrossRef]

14. Tak, P.P.; Firestein, G.S. NF-kappaB: A key role in inflammatory diseases. J. Clin. Investig. 2001, 107, 7-11. [CrossRef]

15. Rosanna, D.P.; Salvatore, C. Reactive oxygen species, inflammation, and lung diseases. Curr. Pharm. Des. 2012, 18, 3889-3900. [CrossRef]

16. Paine, A.; Eiz-Vesper, B.; Blasczyk, R.; Immenschuh, S. Signaling to heme oxygenase-1 and its anti-inflammatory therapeutic potential. Biochem. Pharmacol. 2010, 80, 1895-1903. [CrossRef] [PubMed]

17. Son, Y.; Cheong, Y.-K.; Kim, N.-H.; Chung, H.-T.; Kang, D.G.; Pae, H.-O. Mitogen-Activated Protein Kinases and Reactive Oxygen Species: How Can ROS Activate MAPK Pathways? J. Signal Transduct. 2011, 2011, 792639. [CrossRef] [PubMed] 
18. Schenten, D.; Medzhitov, R. The Control of Adaptive Immune Responses by the Innate Immune System. Adv. Immunol. 2011, 109, 87-124. [CrossRef]

19. Wang, M.; Zhan, Z.; Xiong, Y.; Zhang, Y.; Li, X. Cytotoxic and anti-inflammatory constituents from Momordica cochinchinensis seeds. Fitoterapia 2019, 139, 104360. [CrossRef] [PubMed]

20. Kwon, D.H.; Cha, H.-J.; Choi, E.O.; Leem, S.-H.; Kim, G.-Y.; Moon, S.-K.; Chang, Y.-C.; Yun, S.-J.; Hwang, H.J.; Kim, B.W.; et al. Schisandrin A suppresses lipopolysaccharide-induced inflammation and oxidative stress in RAW 264.7 macrophages by suppressing the NF-KB, MAPKs and PI3K/Akt pathways and activating Nrf2/HO-1 signaling. Int. J. Mol. Med. 2018, 41, 264-274. [CrossRef] [PubMed]

21. Sweet, M.; Hume, D. Endotoxin signal transduction in macrophages. J. Leukoc. Biol. 1996, 60, 8-26. [CrossRef]

22. Rodriguez-Serrano, M.; Barany, I.; Prem, D.; Coronado, M.-J.; Risueno, M.C.; Testillano, P.S. NO, ROS, and cell death associated with caspase-like activity increase in stress-induced microspore embryogenesis of barley. J. Exp. Bot. 2011, 63, 2007-2024. [CrossRef] [PubMed]

23. Kuo, P.C.; Abe, K.Y.; Schroeder, R.A. Oxidative Stress Increases Hepatocyte iNOS Gene Transcription and Promoter Activity. Biochem. Biophys. Res. Commun. 1997, 234, 289-292. [CrossRef]

24. Kunnumakkara, A.B.; Sailo, B.L.; Banik, K.; Harsha, C.; Prasad, S.; Gupta, S.C.; Bharti, A.C.; Aggarwal, B.B. Chronic diseases, inflammation, and spices: How are they linked? J. Transl. Med. 2018, 16, 14. [CrossRef]

25. Sharif, O.; Bolshakov, V.N.; Raines, S.; Newham, P.; Perkins, N.D. Transcriptional profiling of the LPS induced NF- $k B$ response in macrophages. BMC Immunol. 2007, 8, 1. [CrossRef]

26. Wardyn, J.D.; Ponsford, A.H.; Sanderson, C.M. Dissecting molecular cross-talk between Nrf2 and NF-kappaB response pathways. Biochem. Soc. Trans. 2015, 43, 621-626. [CrossRef]

27. Ben-Neriah, Y.; Karin, M. Inflammation meets cancer, with NF-kappaB as the matchmaker. Nat. Immunol. 2011, 12, 715-723. [CrossRef]

28. Yu, M.; Li, H.; Liu, Q.; Liu, F.; Tang, L.; Li, C.; Yuan, Y.; Zhan, Y.; Xu, W.; Li, W.; et al. Nuclear factor p65 interacts with Keap1 to repress the Nrf2-ARE pathway. Cell. Signal. 2011, 23, 883-892. [CrossRef] [PubMed]

29. Chiou, Y.-S.; Huang, Q.; Ho, C.-T.; Wang, Y.-J.; Pan, M.-H. Directly interact with Keap1 and LPS is involved in the antiinflammatory mechanisms of (-)-epicatechin-3-gallate in LPS-induced macrophages and endotoxemia. Free Radic. Biol. Med. 2016, 94, 1-16. [CrossRef]

30. Innamorato, N.G.; Rojo, A.I.; García-Yagüe, Á.J.; Yamamoto, M.; de Ceballos, M.L.; Cuadrado, A. The transcription factor Nrf2 is a therapeutic target against brain inflammation. J. Immunol. 2008, 181, 680-689. [CrossRef] [PubMed]

31. Seo, D.-W.; Yi, Y.-J.; Lee, M.-S.; Yun, B.-S.; Lee, S.-M. Differential Modulation of Lipopolysaccharide-Induced Inflammatory Cytokine Production by and Antioxidant Activity of Fomentariol in RAW264.7 Cells. Mycobiology 2015, 43, 450-457. [CrossRef]

32. Hernández-Ledesma, B.; Hsieh, C.-C.; de Lumen, B. Antioxidant and anti-inflammatory properties of cancer preventive peptide lunasin in RAW 264.7 macrophages. Biochem. Biophys. Res. Commun. 2009, 390, 803-808. [CrossRef]

33. Bist, G.; Pun, N.T.; Magar, T.B.T.; Shrestha, A.; Oh, H.J.; Khakurel, A.; Park, P.-H.; Lee, E.-S. Inhibition of LPS-stimulated ROS production by fluorinated and hydroxylated chalcones in RAW 264.7 macrophages with structure-activity relationship study. Bioorganic Med. Chem. Lett. 2017, 27, 1205-1209. [CrossRef]

34. Ngkelo, A.; Meja, K.; Yeadon, M.; Adcock, I.; Kirkham, P.A. LPS induced inflammatory responses in human peripheral blood mononuclear cells is mediated through NOX4 and Gialpha dependent PI-3kinase signalling. J. Inflamm. 2012, 9, 1. [CrossRef] [PubMed]

35. Wang, X.-L.; Pan, L.-L.; Long, F.; Wu, W.-J.; Yan, D.; Xu, P.; Liu, S.-Y.; Qin, M.; Jia, W.-W.; Liu, X.-H.; et al. Endogenous Hydrogen Sulfide Ameliorates NOX4 Induced Oxidative Stress in LPS-Stimulated Macrophages and Mice. Cell. Physiol. Biochem. 2018, 47, 458-474. [CrossRef]

36. Kaminska, B. MAPK signalling pathways as molecular targets for anti-inflammatory therapy-from molecular mechanisms to therapeutic benefits. Biochim. Biophys. Acta (BBA)_Proteins Proteom. 2005, 1754, 253-262. [CrossRef] [PubMed]

37. Lee, I.T.; Shih, R.H.; Lin, C.C.; Chen, J.T.; Yang, C.M. Role of TLR4/NADPH oxidase/ROS-activated p38 MAPK in VCAM-1 expression induced by lipopolysaccharide in human renal mesangial cells. Cell Commun. Signal. 2012, 10, 33. [CrossRef]

38. Keum, Y.-S.; Yu, S.; Chang, P.P.-J.; Yuan, X.; Kim, J.H.; Xu, C.; Han, J.; Agarwal, A.; Kong, A.-N.T. Mechanism of Action of Sulforaphane: Inhibition of p38 Mitogen-Activated Protein Kinase Isoforms Contributing to the Induction of Antioxidant Response Element-Mediated Heme Oxygenase-1 in Human Hepatoma HepG2 Cells. Cancer Res. 2006, 66, 8804-8813. [CrossRef] 